\title{
NOVA ESPÉCIE DE DENDROPHRYNISCUS DA REGIÃO AMAZÔNICA (AMPHIBIA, ANURA, BUFONIDAE)
}

\author{
Eugenio Izecksohn ${ }^{1}$
}

\begin{abstract}
NEW SPECIES OF DENDROPHRYNISCUS FROM AMAZONIC REGION (AMPHIBIA, ANURA, BUFONIDAE). Dendrophryniscus bokermanni, sp.n. is described from Amazonic Region. It is related to $\mathbf{D}$. minutus but it differs by the larger first finger and body length.

KEY WORDS. Amphibia, Anura, Bufonidae, taxonomy of frogs, new species
\end{abstract}

Cerca de onze diferentes nomes específicos ou sub-específicos já foram incluidos, segundo a literatura, no gênero Dendrophryniscus, mas presentemente apenas três permanecem aceitos para formas desse gênero (FROST, 1985), respectivamente $D$. brevipollicatus Jimenez de la Espada, D. leucomystax Izecksohn e D. minutus (Mellin). As duas primeiras espécies ocorrem na floresta atlântica e a última é forma amazônica. No presente trabalho é apresentada a descrição de uma nova espécie da Região Amazônica.

\section{MATERIAL E MÉTODOS}

Foram examinados 75 exemplares pertencentes às seguintes coleções: Museu Nacional (MN), no Rio de Janeiro, Werner C.A. Bokermann (WCAB), em São Paulo, e do Autor (EI), depositada na Universidade Federal Rural do Rio de Janeiro, em Itaguaí. Uma coluna vertebral foi examinada e, para isso, foi a mesma retirada do exemplar e limpa dos tecidos moles com o emprego de hipoclorito de sódio.

\section{Dendrophryniscus bokermanni, sp.n.}

Figs 1-12

Diagnose. Espécie com as extremidades dos dedos pouco dilatadas, com máculas enegrecidas no ventre e manchas dorsais confluentes, apresentando os machos antebrados espessos e mãos com o I dedo maior do que o II, e possuindo as fêmeas óvulos pigmentados, pequenos e numerosos.

Holótipo EI 5399, macho. BRASIL, Amazonas, Parintins, Vila Amazônica, XI-1972, Jailton Aguiar Arrabal leg. Parátipos. EI 5400-19, obtidos junto com o holótipo; MN 2436 (dois exemplares), Amazonas, Borba; MN 3170 (dois exemplares), Amazonas, Maués, Rio Ipucuitã; WCAB 45456-81, 45484-504,

1) Instituto de Biologia, Universidade Federal Rural do Rio de Janeiro, 23851-970 Itaguaí, Rio de Janeiro, Brasil. Bolsista do CNPq. 


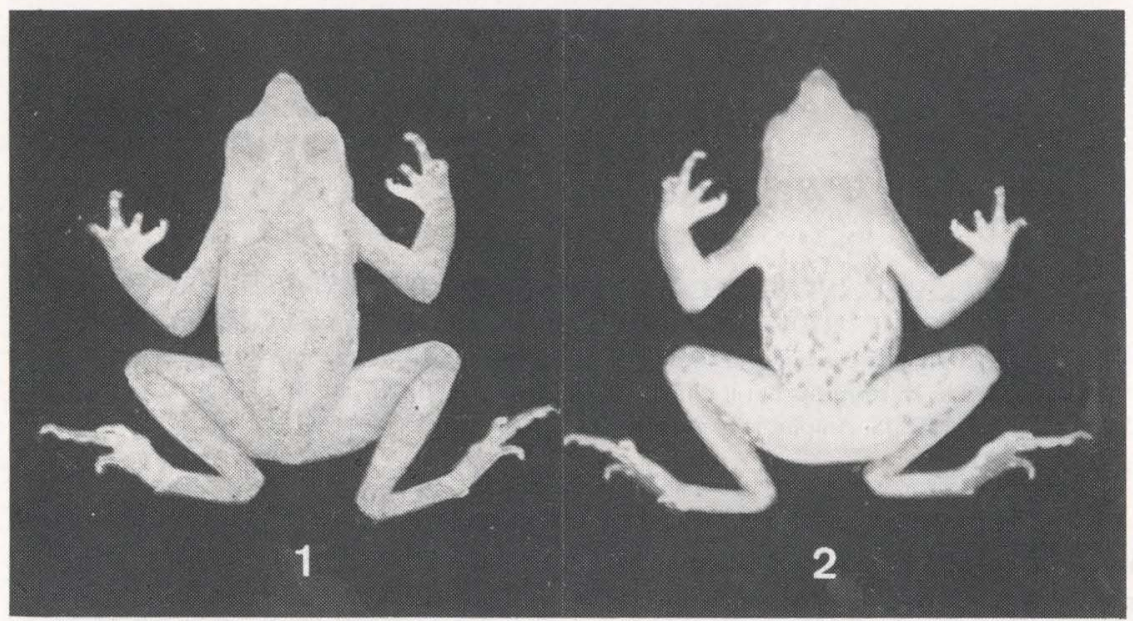

Figs 1-2. Holótipo macho de Dendrophryniscus bokermanni, sp.n., comprimento rostro-anal $22 \mathrm{~mm}$ (Parintins, Amazonas). (1) Dorso; (2) ventre.

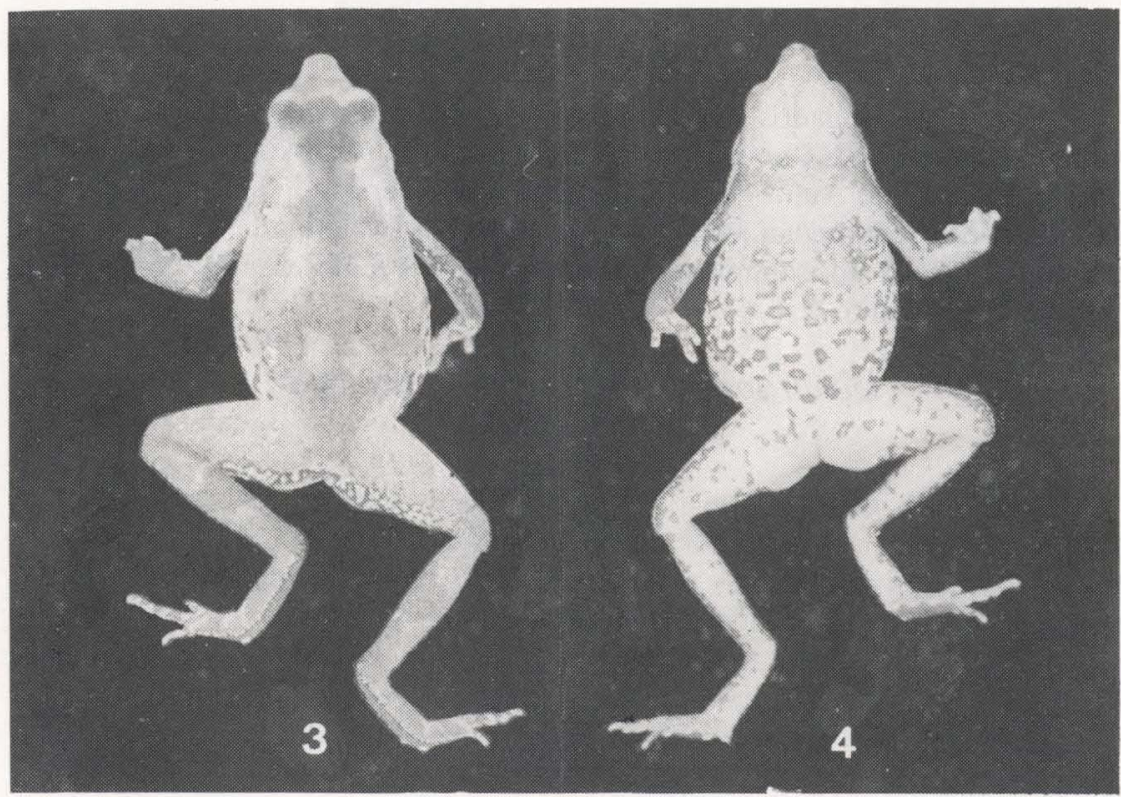

Figs 3-4. Parátipo fêmea de Dendrophryniscus bokermanni, sp.n., comprimento rostro-anal $28 \mathrm{~mm}$ (Parintins, Amazonas). (3) Dorso; (4) ventre. 

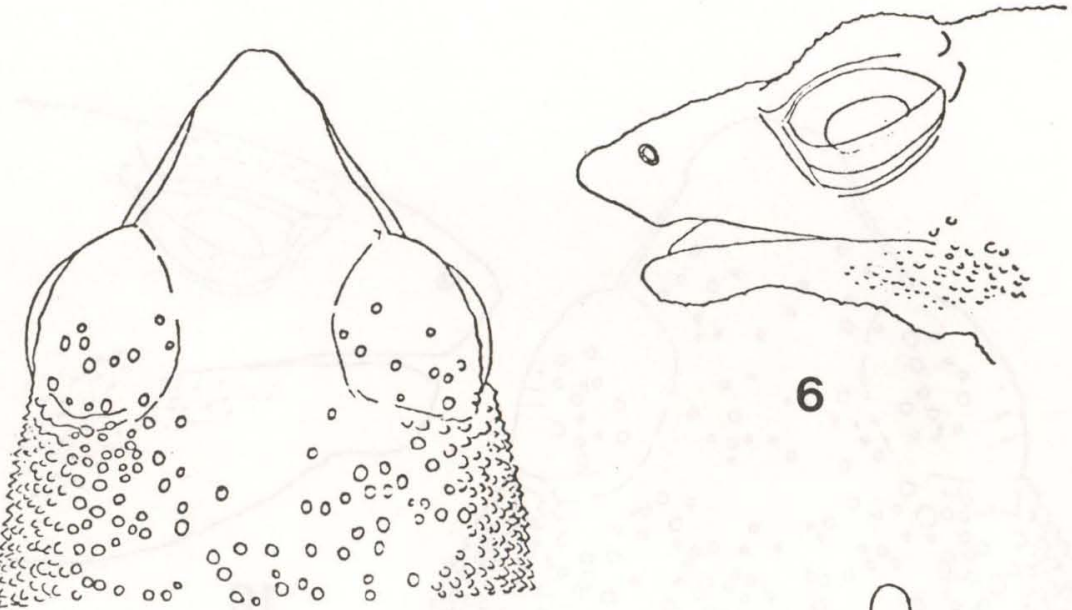

6

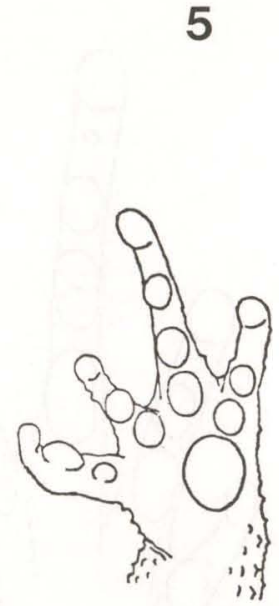

7
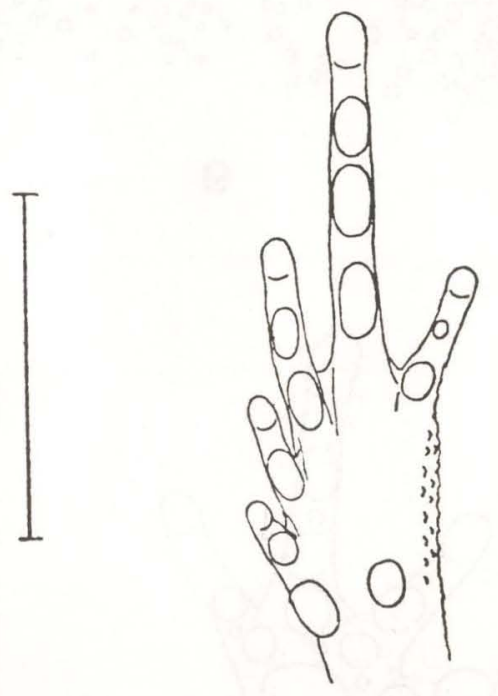

8

Figs 5-8. Holótipo macho de Dendrophryniscus bokermanni, sp.n. (5) Cabeça, vista dorsal; (6) cabeça, perfil; (7) mão, face palmar; (8) pé; face plantar. (Escala $=5 \mathrm{~mm}$ ).

Pará, Jacareacanga; WCAB 7818, Pará, Rio Cururu; WCAB 13275, 13276, Guiana, Onoro.

Descrição. Cabeça triangular em vista dorsal, com seu comprimento correspondendo à largura e contido quase três vezes no comprimento rostroanal; loros planos; canto rostral nítido; focinho afilado e bem projetado adiante da boca no macho, apresentando inferiormente um par de cristas que convergem para a frente; diâmetro ocular correspondente à distância entre o olho e a narina; tímpano ausente; espaço interorbital algo maior do que a largura da 

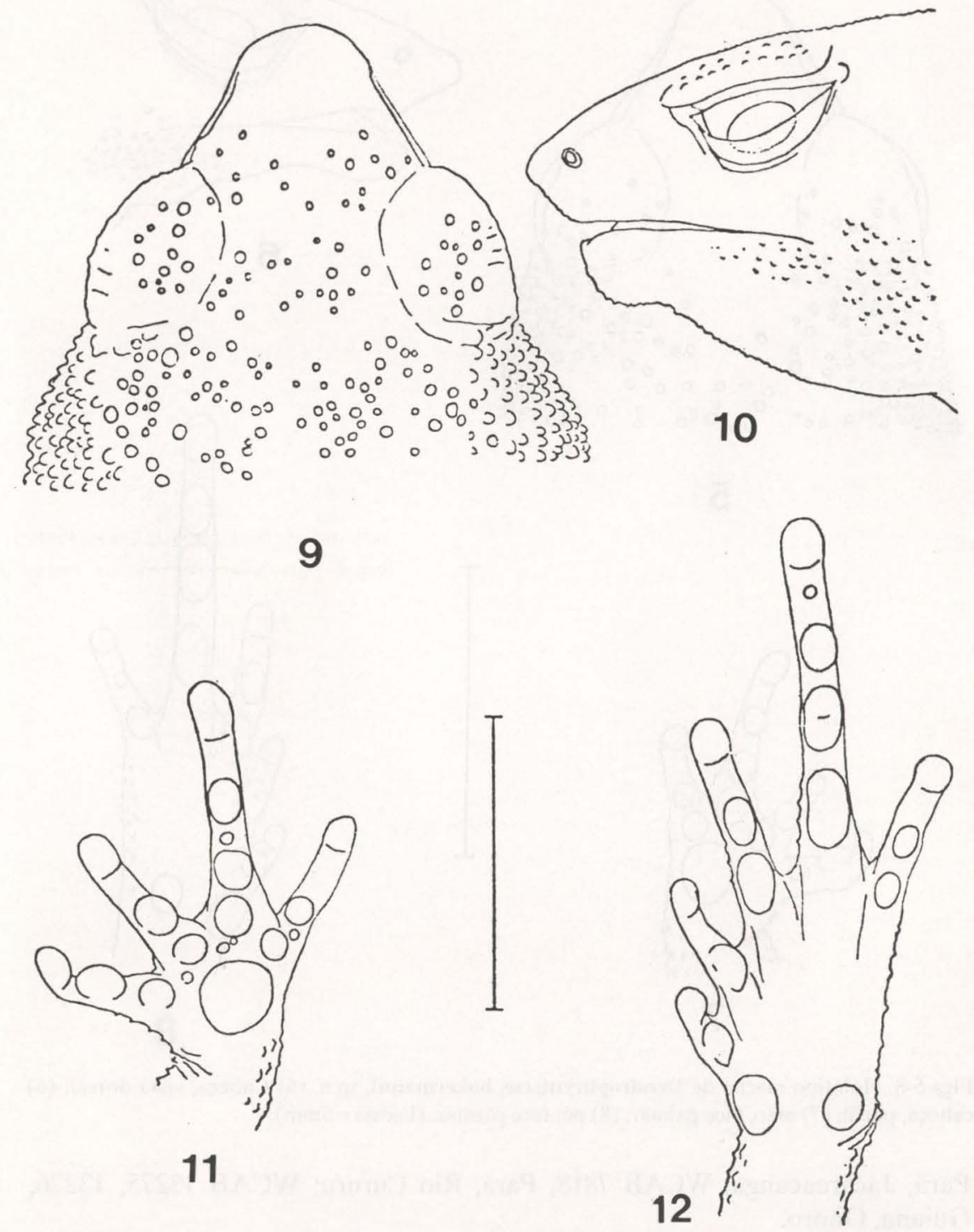

Figs 9-12. Parátipo fêmea de Dendrophryniscus bokermanni, sp.n. (9) cabeça, vista dorsal; (10) cabeça, perfil; (11) mão, face palmar; (12) pé, face plantar. (Escala $=5 \mathrm{~mm})$.

pálpebra superior. Dorso e ventre profusamente recorberto por pequenos grânulos com vértices cônicos. Membros anteriores com os antebraços espessos nos machos e mais delgados nas fêmeas; dedos com as extremidades pouco dilatadas, sendo que o macho apresenta o I dedo mais longo e espesso do que 
o II (ordem crescente de comprimento II-IV-I e III) e a fêmea tem o II dedo algo maior do que o I (ordem crescente de comprimento I-II-IV e III); calos sub-articulares elevados e circulares; alguns calos acessórios pequenos presentes; calo carpal externo grande, elevado e quase circular; calo carpal interno indistinto. Membros posteriores relativamente longos, com coxas robustas; relação comprimento tibial/comprimento rostro-anal variando $(n=22)$ entre 0,48 e 0,54 (média 0,509+0,014); artelhos com as extremidades sem dilatações nítidas, com pequena membrana basal e ordem crescente de comprimento I-II-V-III e IV; calos sub-articulares dos artelhos elípticos e elevados; calos acessórios plantares ausentes; tubérculo metatarsal interno elíptico; tubérculo metatarsal externo circular, menor do que o interno. Colorido dorsal variando entre o pardo-claro e o cinza, havendo no dorso um padrão de manchas mais escuras pouco definidas e fusionadas na linha mediana; ventre esbranquiçado (róseo em material fresco), com pintas ou pequenos ocelos escuros destacados; gula e região esternal com colorido pardo, mais escuro que o dorso, com limites laterais marcados por uma estria escura de cada lado que tem início no canto da boca e atinge a face anterior do úmero; face posterior das coxas com marmoreado pardo-escuro, havendo uma estria horizontal da mesma cor sob a região anal; membros com faixas transversais pouco nítidas em seus segmentos. Dimensões, em milímetros, do holótipo. Comprimento rostro-anal 22,0; comprimento da cabeça 7,5; largura da cabeça 7,0; largura da pálpebra superior 2,0; espaço inter-orbital 2,5; diâmetro ocular 2,5; distância olho-narina 2,5; úmero 7,5; antebraço 5,5; mão 5,5; fêmur 10,0; tíbia 10,5; pé 15,0.

A maior fêmea examinada (EI 5400), com $28 \mathrm{~mm}$ de comprimento rostroanal, contém óvulos pequenos, numerosos e pigmentados. Uma coluna vertebral foi examinada e mostrou articulações entre a oitava vértebra e a sacral e entre essa e o uróstilo.

Diferenciação. D. bokermanni, sp.n. parece se aproximar mais de $D$. minutus (Mellin), uma espécie também amazônica, do que das espécies do sudeste brasileiro, porém seu porte maior e o alongamento do I dedo separam a nova espécie das demais do gênero. O colorido de D. bokermanni pode sugerir o de Ramphophryne proboscidea (Boulenger), da Bahia, mas o tamanho maior, a presença de glândulas paratóides e a forma peculiar do focinho dessa última espécie as distinguem prontamente.

Etimologia. O nome é uma homenagem a Werner C.A. Bokermann por sua significativa contribuição ao conhecimento dos anfíbios anuros brasileiros.

Comentários. D. bokermanni, como sugerem seus ovos pigmentados e numerosos, deve criar suas larvas em poças de água acumuladas no solo, como fazem D. minutus da Amazonia (Duellman \& Lynch, 1969) e D. leucomystax da mata atlântica (Izecksohn e Cruz, 1972), diferindo de D. brevipollicatus, também da mata atlântica, que desova em bromeliáceas (LUTZ, 1932; CARVALHO, 1949; IZECKSOHN \& CRUZ, 1972). Em D. bokermanni o dimorfismo sexual é acentuado, observando-se nos machos focinho mais afilado, antebraço mais espesso e II dedo menor do que o I. Essa espécie parece se distribuir amplamente pelos afluentes do baixo Amazonas. A forma da mão, com o I dedo mais longo 
do que o observado nas demais espécies do gênero, sugere um relacionamento maior com Bufo e isso talvez indique ser essa a mais primitiva entre as espécies conhecidas de Dendrophryniscus.

\section{REFERÊNCIAS BIBLIOGRÁFICAS}

CARVALHO, A.L. 1949. Notas sobre os hábitos de Dendrophryniscus brevipollicatus Espada (Amphibia, Anura). Rev. Brasil. Biol. 9: 223-227.

DUELLMAN, W.E. \& J.D. LYNCH. 1969, Descriptions of Atelopus tadpoles and their relevance to Atelopodid classification. Herpetologica 25: 231-240.

FROST, D.R. 1985. Amphibian species of the world: a taxonomic and geographical reference. Lawrence, Allen Press and The Association of Systematics Collections, $V+732 p$.

IZECKSOHN, E. \& C.A.G. DA CRUZ. 1972. Notas sobre os girinos de Dendrophryniscus leucomystax Izecksohn e D. brevipollicatus Espada (Amphibia, Anura, Bufonidae). Arq. Univ. Fed. Rural Rio de J. 2: 63-69.

LUTZ, A. 1932. Sur la biologie des batraciens du Brésil. C.R. Soc. Biol., Paris, 109: $755-756$.

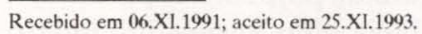

